\title{
A GESTÃO DO PLANEJAMENTO DE TAREFAS MATEMÁTICAS POR PROFESSORAS DOS ANOS INICIAIS
}

\author{
LA GESTIÓN DE LA PLANIFICACIÓN DE TAREAS MATEMÁTICAS \\ POR MAESTROS DE LOS PRIMEROS AÑOS
}

\section{MANAGEMENT OF MATHEMATICAL TASK PLANNING BY TEACHERS} FROM THE EARLY YEARS

\author{
Lindomar Santana Aranha Pereira \\ Universidade Estadual do Sudoeste da Bahia - Brasil \\ Tania Cristina Rocha Silva Gusmão \\ Universidade Estadual do Sudoeste da Bahia - Brasil
}

\section{RESUMO}

Este artigo apresenta o recorte de uma pesquisa a qual teve como objetivo principal analisar o processo de gestão de tarefas matemáticas de um grupo de professoras dos Anos Iniciais do Ensino Fundamental, antes e depois de um processo formativo. A investigação de abordagem qualitativa na modalidade da pesquisa-ação foi desenvolvida por meio de um grupo de formação, envolvendo a pesquisadora e professoras dos Anos Iniciais do Ensino Fundamental de uma escola pública. Os dados foram produzidos através de encontros presenciais formativos, entrevistas semiestruturadas, sequências de tarefas planejadas pelas professoras e observação direta de aula. A gestão de tarefas é entendida nesse trabalho como um processo que envolve a gestão do planejamento, da implementação e da avaliação das tarefas matemáticas. Especificamente para este artigo, explicitamos a análise desenvolvida acerca do processo de gestão do planejamento. Os dados analisados apontam que, embora as professoras reconheçam a importância do planejamento, demonstram dificuldades ao planejarem devido à falta de domínio de conhecimentos didático-matemáticos, revelando que estudam pouco ou não estudam, e normalmente refutam os conteúdos que têm dificuldades.

Palavras-chave: Ensino de Matemática. Gestão de Tarefas. Critérios de Idoneidade Didática. 


\title{
A GESTÃo DO PLANEJAMENTO DE TAREFAS MATEMÁTICAS POR PROFESSORAS DOS ANOS INICIAIS
}

\section{RESUMEN}

Este artículo presenta un extracto de una encuesta cuyo objetivo principal era analizar el proceso de gestión de tareas matemáticas de un grupo de maestros en los primeros años de la escuela primaria, antes y después de un proceso formativo. La investigación de un enfoque cualitativo en forma de investigación de acción se desarrolló a través de un grupo de capacitación, que involucró al investigador y los maestros de los primeros años de la escuela primaria en una escuela pública. Los datos se produjeron a través de reuniones de capacitación presenciales, entrevistas semiestructuradas, secuencias de tareas planificadas por los maestros y observación directa de la clase. La gestión de tareas se entiende en este trabajo como un proceso que implica la gestión de la planificación, implementación y evaluación de tareas matemáticas. Específicamente para este artículo, explicamos el análisis desarrollado sobre el proceso de gestión de planificación. Los datos analizados muestran que, aunque los maestros reconocen la importancia de la planificación, demuestran dificultades en la planificación debido a la falta de dominio del conocimiento didáctico: matemáticos, revelando que estudian poco o no estudian, y generalmente refutan los contenidos que tienen dificultades.

Palabras clave: Enseñanza de las matemáticas. Gestión de tareas. Criterios didácticos de idoneidad.

\begin{abstract}
This article presents an excerpt from a research which had as main objective to analyze the process of managing mathematical tasks of an Early Years Elementary School group of teachers, before and after a formative process. The investigation of a qualitative approach in the form of action-research was developed through a training group, involving the researcher and Early Years Elementary School teacher in a public school. The data were produced through face-to-face training meetings, semi-structured interviews, sequences of tasks planned by the teachers and direct observation of the class. Task management is understood in this work as a process that involves the management of the planning, implementation and evaluation of mathematical tasks. Specifically, for this article, we explain the analysis developed about the planning management process. The analyzed data show that, although the teachers recognize the importance of planning, they demonstrate difficulties in planning due to the lack of mastery of didactic-mathematical knowledge, revealing that they study little or do not study, and usually refute content that they have difficulties.
\end{abstract}

Keywords: Mathematics teaching. Task Management. Didactic Suitability Criteria.

\section{Introdução}

Este artigo apresenta um recorte de uma pesquisa desenvolvida no Programa de PósGraduação em Ensino - PPGEn da Universidade Estadual do Sudoeste da Bahia - UESB, vinculada ao Grupo de Estudos e Pesquisas Museu Pedagógico: Didática das Ciências Revista RBBA $\mid$ Revista Binacional Brasil Argentina 


\section{A GESTÃo DO PLANEJAMENTO DE TAREFAS MATEMÁTICAS POR PROFESSORAS DOS ANOS INICIAIS}

Experimentais e da Matemática - GDICEM cujo objetivo foi o de analisar o processo de gestão de tarefas matemáticas de um grupo de professores dos Anos Iniciais do Ensino Fundamental, antes e depois de um processo formativo.

O GDICEM, propõe discutir a compreensão dos objetos matemáticos por parte de professores e estudantes da Educação Básica e, ainda, o desenvolvimento de competências profissionais na formação de professores de matemática, buscando melhorias nas práticas de ensino por meio de inovações pedagógicas. O Grupo tem concentrado seus estudos na literatura sobre Desenho de Tarefas (GUSMÃO, 2016) e no Enfoque Ontossemiótico da Cognição e Instrução Matemática (EOS), um referencial teórico - metodológico criado pelo matemático e pesquisador espanhol Juan Godino em colaboração com outros pesquisadores e, que articula diferentes ferramentas teóricas sobre o conhecimento matemático, seu ensino e aprendizagem.

Envolto nessa contextualização, o trabalho proposto, nasce da identificação de lacunas relacionadas à forma como professores de matemática da Rede Municipal de Ensino da cidade de Guanambi - BA conduzem o desenvolvimento das tarefas, demonstrando uma dificuldade de gestão na sala de aula. Essa problemática nos levou a inferir inicialmente que as lacunas poderiam advir da falta de percepção, por parte do professor, das tarefas como um elemento potenciador do processo de aprendizagem matemática e da falta de domínio de conhecimentos.

Deste modo, destaca-se que o tratamento dado pelos professores às tarefas matemáticas - a atenção dada ao planejamento destas, a maneira como as conduzem em sala de aula, o papel que é atribuído a elas no processo de aprendizagem, pode tornar prazeroso ou não o contato do aluno com o conhecimento matemático, e pode definir a intensidade da relação desse aluno com a Matemática. É neste contexto que se insere a temática da gestão de tarefas e, especificamente, gestão do planejamento de tarefas, nesse processo de investigação. Norteada pela questão: como se dá a gestão de tarefas matemáticas por um grupo de professores dos Anos Iniciais do Ensino Fundamental da rede municipal de ensino de Guanambi, a pesquisa realizada, pautada em uma intervenção no campo da formação continuada, direcionou-se pela possibilidade de as professoras refletirem sobre a forma como planejam e como conduzem a implementação das tarefas na sala de aula, além de se conscientizarem da possibilidade da sua prática gestora influenciar diretamente no êxito da aprendizagem do aluno.

As "tarefas matemáticas" são compreendidas como situações de aprendizagem escolhidas pelo professor e apresentadas ao aluno, para intermediar o processo de ensino e aprendizagem da matemática. Estas podem aparecer no início, no meio ou no final da aula, em

Revista RBBA $\mid$ Revista Binacional Brasil Argentina 


\section{A GESTÃo DO PLANEJAMENTO DE TAREFAS MATEMÁTICAS POR PROFESSORAS DOS ANOS INICIAIS}

forma de projetos, exercícios, jogos, situações-problemas, (PONTE, 2005; GUSMÃO, 2016, 2019) sejam desenhadas ${ }^{\mathrm{i}}$, redesenhadas pelo professor (GUSMÃO, 2016) ou retiradas do livro didático. No início da aula, a tarefa pode aparecer como atividade para diagnosticar os conhecimentos que alunos já trazem antes da apresentação de um conteúdo novo; no meio e no final da aula pode ser utilizada para intermediar a aprendizagem de conceitos a serem aprendidos. Portanto, assumem um papel importante no processo de construção e/ou compreensão dos conceitos matemáticos.

Salienta-se que a temática, objeto de estudo dessa pesquisa, se apresenta de forma relevante e merece especial atenção para estudos e pesquisas, pois, embora o ensino da matemática tenha se constituído em campo de estudos e reflexões de pesquisadores nas diversas etapas e modalidades de ensino, todavia, no que se refere ao estudo da gestão de tarefas matemáticas, as discussões epistemológica ou metodológica são poucas, ou inexistem no meio acadêmico.

Dessa forma, estruturamos o presente Artigo apresentando, a seguir o enquadramento teórico do estudo, abordando brevemente o tema Gestão de Tarefas Matemáticas e, nesse contexto o que chamamos de Gestão de Planejamento; na sequência, traçamos um pequeno mapa do percurso metodológico, seguido dos resultados obtidos e, por fim, as principais conclusões do estudo.

\section{A Gestão de Tarefas Matemáticas}

O conceito de gestão, ao longo dos anos vem sendo adaptado e utilizado amplamente no campo educacional, onde vem sendo empregado nas diversas dimensões, inclusive ganhando “corpo" na dimensão pedagógica.

Alguns autores têm apresentado estudos e pesquisas relacionadas à gestão em sua dimensão pedagógica. Ponte (2005), traz estudos sobre a Gestão Curricular; Vasconcelos (2012) e Weinstein e Novodvorsky (2015) abordam sobre a Gestão na Sala de Aula; e Gauthier (2013), apresenta estudos e pesquisas sobre Gestão da Matéria e Gestão da Classe. No entanto, ressalta-se a ausência de estudos direcionados especificamente para caracterizar a gestão de tarefas na sala de aula. 


\section{A GESTÃo DO PLANEJAMENTO DE TAREFAS MATEMÁTICAS POR PROFESSORAS DOS ANOS INICIAIS}

Assim, para elaboração do nosso constructo, situamos a gestão de tarefas no âmbito da dimensão pedagógica, e dialogamos com as abordagens dos autores anteriormente mencionados. A gestão da matéria é definida por Gauthier como

Todos os enunciados relativos ao planejamento, o ensino e à avaliação de uma lição ou de uma parte de uma lição. Essa dimensão está ligada ao conjunto das operações organizadas para levar o aluno a aprender o conteúdo: maneira de estruturar a lição, tipo de perguntas feitas, exercícios propostos, procedimentos de avaliação das aprendizagens. (GAUTHIER, 2013, p. 436).

Sousa (2018, p.43) define gestão de tarefas como "toda a parte de aplicação e condução da tarefa - preparação inicial, contextualização, perguntas, provocações e problematização feitas, distribuição do tempo, interação professor-aluno e aluno - aluno, entre outros arranjos".

$\mathrm{Na}$ presente pesquisa, validamos as definições referenciadas e ampliamos a defesa dos autores, tratando a gestão de tarefas como "um conjunto de ações desenvolvidas pelo professor para explorar de forma eficiente as tarefas em sala de aula, visando ao alcance dos objetivos estabelecidos", cuja finalidade é fazer com que as tarefas contribuam efetivamente com a aquisição da aprendizagem dos alunos. Corroboramos, portanto, com Lück (2009, p. 25), quando defende que "o fim último da gestão é a aprendizagem efetiva e significativa dos alunos, de modo que, no cotidiano que vivenciam na escola desenvolvam as competências que a sociedade demanda".

Para Roldão e Almeida (2018), o processo de gerir é estruturado em algumas dimensões: analisar, decidir, concretizar a decisão, avaliar o desenvolvimento e os resultados que decorrem da decisão, prosseguir, reorientar ou abandonar a decisão tomada.

Nessa mesma vertente, Lück (2009), organiza a gestão no âmbito escolar em dimensões agrupadas em duas áreas - organização e implementação - de acordo com sua natureza.

As dimensões de organização dizem respeito a todas aquelas que tenham por objetivo a preparação, a ordenação, a provisão de recursos, a sistematização e a retroalimentação do trabalho a ser realizado. E as dimensões de implementação são aquelas desempenhadas com a finalidade de promover, diretamente, mudanças e transformações no contexto escolar. (LÜCK, 2009, p. 26).

A partir destes pressupostos defendidos pelas autoras, depreendemos a ideia de que o conjunto de ações a que nos referimos no processo de gestão de tarefas, deve envolver os Revista RBBA $\mid$ Revista Binacional Brasil Argentina 


\section{A GESTÃo DO PLANEJAMENTO DE TAREFAS MATEMÁTICAS POR PROFESSORAS DOS ANOS INICIAIS}

processos de planejamento, implementação e avaliação. E, para gerenciar as tarefas na sala de aula o professor deve garantir que cada um desses processos seja realizado com a qualidade necessária para que o fim último da gestão [a aprendizagem efetiva e significativa] seja alcançado com sucesso.

Sobre o processo de "Gestão de Tarefas Matemáticas", focamos em duas dimensões: gestão global e gestão pontual. A primeira se refere ao processo de gestão de forma geral e a segunda, trata pontualmente da gestão do Planejamento, da Implementação e da Avaliação (GODINO, 2011; PONTE, 2005; GAUTHIER, 2013; GUSMÃO, 2016). Consideramos que a gestão de tarefas matemáticas, do ponto de vista geral, envolve a postura pedagógica construída e adotada pelo professor e a relação de domínio que o professor estabelece com o conhecimento.

A postura pedagógica adotada pelo professor, normalmente reflete o modelo pedagógico que está subjacente ao seu fazer pedagógico diário. Essa postura é determinante na dinâmica que envolve o processo de ensino - aprendizagem e a relação professor-aluno. Além disso, define o perfil profissional e a perspectiva pedagógica colocada em prática por ele na sala de aula.

Nesse sentido, defendemos que uma boa e adequada gestão de tarefas perpassa pela adoção de uma postura pedagógica que valorize a participação e a autonomia do aluno no processo de aprendizagem e que tenha o professor como um mediador do conhecimento, um professor que "[...] deixa uma parte importante do trabalho de descoberta e de construção do conhecimento para os alunos realizarem" (PONTE, 2005, p. 12); além disso, um professor que considere a tarefa uma ferramenta importante para o ensino da Matemática, com atenção especial à condução da sua resolução na sala de aula.

Quanto à relação de domínio que o professor estabelece com o conhecimento, esta perpassa pelo domínio dos conhecimentos didático - matemáticos, considerados por Godino (2009; 2011), como necessários para que o professor desenvolva uma prática de ensino mais adequada possível. $\mathrm{O}$ autor refere-se aos conhecimentos didático - matemáticos como o complexo de conhecimentos e competências profissionais colocados em prática para promover a aprendizagem de seus alunos. Inclui o conhecimento didático e o conhecimento do conteúdo matemático, além do controle das transformações que devem ser aplicadas ao conteúdo para sua difusão e comunicação.

De acordo com Godino (2009) os conhecimentos didático-matemáticos estão entrelaçados e se constituem como componentes do conhecimento do professor e são Revista RBBA Revista Binacional Brasil Argentina 


\section{A GESTÃo DO PLANEJAMENTO DE TAREFAS MATEMÁTICAS POR PROFESSORAS DOS ANOS INICIAIS}

transformados em critérios que fundamentam a avaliação da adequação dos processos de ensino e aprendizagem da matemática, denominados Critérios de Idoneidade Didática.

A idoneidade didática de um processo de instrução é definida como o grau em que esse processo (ou parte dele) reúne certas características que lhe permite ser qualificado como idôneo (ótimo ou adequado), para conseguir a articulação entre o ensino e a aprendizagem, levando em consideração as circunstâncias e os recursos disponíveis. (GODINO et al. 2016, p.294)

Os critérios de idoneidade didática, a priori são princípios que orientam "como as coisas devem ser feitas", e a posteriori, servem para avaliar o processo de estudo efetivamente implementado (BREDA; FONT e LIMA, 2015, p.5). Vejamos uma descrição detalhada de cada um deles:

Idoneidade Epistêmica: refere-se a que a Matemática ensinada seja "boa matemática". Para isso, além de tomar como referência o currículo prescrito, se trata de tomar como referência a Matemática institucional que é apresentada pelo currículo.

Idoneidade Cognitiva: expressa o grau em que as aprendizagens pretendidas/implementadas estão na zona de desenvolvimento proximal9 dos alunos, assim como a proximidade das aprendizagens adquiridas às que foram pretendidas ou implementadas.

Idoneidade Emocional: distribuição temporal dos estados afetivos (atitudes, emoções, afetos, motivações) de cada aluno em relação com os objetos matemáticos e com o processo de estudo seguido.

Idoneidade Interacional: grau em que os modos de interação permitem identificar e resolver conflitos de significado e favorecem a autonomia da aprendizagem.

Idoneidade Mediacional: grau de disponibilidade e adequação dos recursos materiais e temporais necessários para o desenvolvimento do processo de ensino-aprendizagem.

Idoneidade Ecológica: grau de adaptação do processo de estudo ao projeto educativo do centro, as diretrizes curriculares, às condições do entorno social. (BREDA; FONT e LIMA, 2015, p.5)

Destaca-se que o professor como um bom gestor de tarefas, precisa realizar uma gestão adequada do planejamento, da implementação e da avaliação das tarefas na sala de aula, que perpassa pela postura pedagógica e domínio dos conhecimentos didático-matemáticos. 


\section{A GESTÃO DO PLANEJAMENTO DE TAREFAS MATEMÁTICAS POR}

PROFESSORAS DOS ANOS INICIAIS

\subsection{A Gestão do Planejamento de tarefas}

O planejamento constitui uma etapa importante da atividade docente, tornando-se essencial para o processo de gestão. É por meio dele que o professor estabelece os objetivos, metas, ações e recursos necessários à produção dos resultados que convergem para a aprendizagem dos alunos.

No campo educacional, ressaltando o que deve representar o momento do planejamento para o professor, Vasconcelos $(2012$, p. 80) define-o como um "processo contínuo e dinâmico, de reflexão, tomada de decisão, colocação em prática e acompanhamento". Para o autor, este momento vai além do simples registro de um plano ou roteiro de trabalho. O planejamento deve prever os acontecimentos da aula, as formas como os alunos responderão as tarefas propostas e como essas respostas podem ser utilizadas para promover a aprendizagem do conteúdo (SERRAZINA, 2017).

Nesta mesma perspectiva, Wadsworth $(1994$, p. 221$)$ ressalta que se trata de “[...] um meio para se programar as ações docentes, mas é também um momento de pesquisa e reflexão".

Das definições acima, depreendemos a ideia de gestão do planejamento de tarefas matemáticas como um conjunto de decisões tomadas pelo professor de forma reflexiva para realizar, posteriormente, a implementação das tarefas na sala de aula. É uma ação que envolve a identificação das necessidades e potencialidades dos alunos, a definição de onde se pretende chegar, o que deve ser feito, quando, como e em que sequência deve ser feito. É por meio da gestão do planejamento que o professor visualiza, antecipadamente, a condução da realização das tarefas na sala de aula.

Esta premissa remete ao professor a responsabilidade de se atentar para a importância do planejamento das tarefas a serem implementadas nas aulas de matemática, para que de fato elas venham a cumprir com os objetivos por ele traçados. Sobre esta questão, Gusmão (2016) afirma que

[...] as tarefas devem ser muito bem planejadas e deixar claro as intenções educativas que se espera alcançar, pois, a riqueza de uma tarefa bem planejada com fins educativos contribui para a melhoria do ensino e auxilia o professor a perceber o alcance de suas ações no desenvolvimento da cognição e metacognição ${ }^{\text {ii }}$ matemática de seus alunos. (GUSMÃO, 2016, p. 185) 


\section{A GESTÃo DO PLANEJAMENTO DE TAREFAS MATEMÁTICAS POR PROFESSORAS DOS ANOS INICIAIS}

Nesse sentido, as intenções educativas "agem" como importante termômetro para o processo de ensino. Estas aparecem como ponto de partida do planejamento. É quando o professor define onde pretende chegar com determinada tarefa (objetivos); com qual finalidade ela será utilizada - verificar o que o aluno aprendeu, reforçar a aprendizagem de um conteúdo, investigar as capacidades e dificuldades dos alunos ou intermediar a exploração de um conceito; assim como, as estratégias de ensino, quando define o que vai ser feito por (ele) professor e pelo aluno (PONTE, 2005).

Destacamos aqui alguns elementos que consideramos inerentes ao processo de planejamento das tarefas matemáticas, os quais devem servir de base e sustentação para realização desse processo pelo professor. Um deles é o estudo. Não há como realizar um bom planejamento sem estudo (GUSMÃO, 2016). É por meio do estudo que o professor adquire o domínio dos conhecimentos, necessários para uma "boa" gestão do planejamento e, por conseguinte, ensinar com a melhor qualidade possível e favorecer a aprendizagem de seus estudantes.

Outro elemento importante é a escolha das tarefas que são apresentadas para os alunos. De acordo com Steele (2001, p. 42): "nenhuma outra decisão que o professor toma tem um impacto tão grande nas oportunidades de os alunos aprenderem e na sua percepção do que é Matemática, como a seleção ou criação de tarefas". Compreendemos que esta seleção pode ser feita no livro didático, em outra fonte ou por meio da criação/desenho de tarefas, desde que seja feita uma "boa" escolha, com tarefas que sejam adequadas às necessidades e potencialidades dos alunos. Consideramos aqui como potencialidades, a "capacidade" de aprendizagem, ou seja, o nível de desenvolvimento cognitivo (WADSWORTH, 1994) que os alunos possuem. E consideramos como necessidades, aquilo que o aluno precisa aprender.

Gusmão (2016, p. 183), ratifica essa ideia afirmando que “[...] o que os estudantes aprendem está intimamente relacionado às tarefas que oferecemos a eles". Por isso, escolher "boas tarefas" é essencial para promover o desenvolvimento e aquisição de conceitos matemáticos pelos estudantes.

Sobre a escolha das tarefas, Serrazina (2017) afirma que o professor tem de escolher tarefas com critério, com uma visão crítica sobre os recursos, pensar nas estratégias da aula, nos materiais a utilizar, lembrando também o nível etário dos alunos com quem está trabalhando. Mas, afinal, como fazer uma "boa" escolha de tarefas matemáticas? Podemos 


\section{A GESTÃo DO PLANEJAMENTO DE TAREFAS MATEMÁTICAS POR PROFESSORAS DOS ANOS INICIAIS}

sinalizar que o professor precisa escolher tarefas que atendam a seus objetivos de ensino, tarefas que contribuam de fato com a aprendizagem na sala de aula. Situamos aqui a necessidade de diversificação das tarefas (PONTE, 2005), tendo em conta as múltiplas necessidades postas na sala de aula, seja do grupo como um todo, seja com relação a necessidade de desenvolvimento de habilidades específicas em cada aluno. Essa diversificação perpassa naturalmente pelos diferentes tipos de tarefas, tarefas com características diferentes, e diferentes níveis de demanda cognitiva (STEIN et al., 2009). Mesmo considerando a importância da diversificação das tarefas, destacamos a utilização das tarefas abertas, que se caracterizam como tarefas intelectualmente inteligentes, desafiadoras, capazes de levar os estudantes a se expressarem com liberdade e autonomia, proporcionando, assim, boas condições para o seu desenvolvimento cognitivo e metacognitivo (GUSMÃO, 2016; PONTE, 2005). Tarefas que exige um professor com postura diferenciada, que privilegia o levantamento de questões, o estímulo à discussão e à reflexão (GUSMÃO, 2016).

Incluímos neste contexto o desenho e o (re)desenho de tarefas, conforme discorre Pochulu et al. (2013), Gusmão (2016) e Sousa (2018), como uma boa estratégia de escolha das tarefas matemáticas, pois, o ato de desenhar ou (re)desenhar tarefas, pode funcionar como ponto de partida para construção de conhecimentos e favorecer o desenvolvimento de processos reflexivos por parte do professor (SOUZA et al. 2019), embora seja um processo complexo que requer tempo, paciência, dedicação e muito estudo (GUSMÃO, 2016).

Para Pochulu et al. (2013), citado por Gusmão (2016, p. 188), “o desenho de tarefas matemáticas é o processo de elaboração, criação e preparação de situações matemáticas a serem aplicadas em sala de aula e o redesenho, faz referência ao processo de adaptação, adequação e ajustes das mesmas". E, neste processo de desenho e redesenho de tarefas por parte do professor, ressaltamos o uso dos critérios de idoneidade didática como um rico referente teórico.

Gusmão (2016; 2019) assinala que o desenho de tarefas é uma etapa demorada, o qual requer muitas escritas e reescritas, devendo o professor atentar-se para a linguagem, a apresentação, e, sobretudo, para os elementos que faz dela uma "boa tarefa", ou seja, deve observar se a tarefa desenhada é autêntica, interessante, divertida, variada e desafiadora (mas ao alcance da capacidade de resolução dos estudantes).

Ademais, no exercício de planejar as tarefas, é importante que o professor, considere, sobretudo, os fatores que fazem parte do contexto da sala de aula, como, por exemplo, o tempo, o espaço, os recursos disponíveis, a "capacidade" de aprendizagem dos alunos, dentre outros

\begin{tabular}{l|l} 
Revista RBBA & Revista Binacional Brasil Argentina
\end{tabular} 


\section{A GESTÃO DO PLANEJAMENTO DE TAREFAS MATEMÁTICAS POR}

que interferem significativamente no sucesso da realização das tarefas. Tais fatores, também, são evidenciados por Godino (2011) nos critérios de idoneidade didática, os quais devem ser utilizados à priori como princípios orientadores de "como as tarefas devem ser planejadas para serem realizadas na sala de aula".

\section{Percurso Metodológico}

A investigação, desenvolvida em uma abordagem qualitativa, na modalidade da pesquisa-ação (TRIPP, 2005), foi desenvolvida em três fases: planejamento, implementação e avaliação que se caracterizaram como um movimento cíclico, formando uma espiral reflexiva. A principal fonte de produção de dados foi um processo formativo/interventivo, realizado por meio de um grupo de estudos, envolvendo a pesquisadora e três professoras que atuam do $1^{\circ}$ ao $3^{\circ}$ ano do Ensino Fundamental de uma escola pública de Guanambi-Bahia; além de sequências de tarefas elaboradas pelas professoras; execução de aulas e entrevistas semiestruturadas. O processo de formação foi materializado em 08 (oito) encontros que aconteceram de junho a outubro de 2018, na escola (campo empírico desta pesquisa). Este processo permitiu às professoras pensarem na maneira como realizam a gestão de tarefas matemáticas na sala de aula e os reflexos desse processo na aprendizagem dos estudantes.

Um dos fatores que determinou a escolha da escola como lócus da pesquisa foi o seu resultado no IDEB ${ }^{\text {iii }}$ 2015, (por não ter apresentado crescimento em relação à avaliação anterior e/ou atingido a meta estabelecida pelo governo - resultado 4,3/meta projetada 5,1 - com destaque para o desempenho da escola na Prova Brasil 2015 de Matemática), indicando assim, uma possível fragilidade e/ou lacuna no processo de ensino da matemática, embora este não seja fator preponderante no resultado da referida avaliação.

Os dados produzidos foram organizados e analisados por meio das seguintes unidades temáticas: (i) a gestão do planejamento de tarefas; (ii) a gestão da implementação de tarefas e (iii) a gestão da avaliação de tarefas, que emergiram da revisão da literatura e dos objetivos que direcionaram a pesquisa e foram definidas levando em consideração a análise textual discursiva.

A unidade temática - a gestão do planejamento de tarefas - reuniu os dados referentes à prática das professoras de planejar as tarefas, tendo como balizadores as sequências matemáticas elaboradas antes e depois do processo formativo e os discursos produzidos pelas professoras nas entrevistas. A unidade temática - a gestão da implementação de tarefas -

Revista RBBA Revista Binacional Brasil Argentina 


\section{A GESTÃo dO PLANEJAMENTO DE TAREFAS MATEMÁTICAS POR}

PROFESSORAS DOS ANOS INICIAIS

apresentou os dados referentes à condução do processo de implementação das tarefas na sala de aula, tendo como referência as aulas executadas e as informações apresentadas nas entrevistas e nos encontros e, a unidade temática - a gestão da avaliação de tarefas - reuniu dados sobre as práticas avaliativas do professor no contexto das tarefas. Esta dimensão, numa perspectiva mais reflexiva, envolveu a identificação da capacidade do professor de analisar e avaliar didaticamente a sua própria prática, em um movimento de autorreflexão e autoconhecimento.

Para discutir as unidades temáticas, tomamos como referência os Critérios de Idoneidade Didática, os quais são utilizados como recurso para qualificar a idoneidade didática presente na gestão das tarefas realizadas pelas professoras. Considerando seu grau de adequação, as idoneidades foram avaliadas usando o continuum de três valorações: alta, média e baixa.

Destacamos neste trabalho a análise e discussão dos dados referentes à gestão do planejamento de tarefas demonstrada pelas professoras. A análise desse processo apontou as percepções das professoras sobre o processo de planejamento de tarefas, que emergiram das entrevistas realizadas antes e depois da formação, assim como das sequências matemáticas planejadas e replanejadas.

\section{Resultados e discussões}

Da análise dos dados extraímos os resultados consistentes e respostas convincentes às questões formuladas no início da investigação (FIORENTINI; LORENZATTO, 2012).

A análise e discussão dos dados sobre a gestão do planejamento, foi focada nos conhecimentos didático - matemático e na relação das professoras com o estudo (GUSMÃO, 2016), com a escolha das tarefas (STEELE, 2001) e com a idoneidade didática (GODINO, 2011), fatores inerentes ao processo de gestão do planejamento e organizada em duas etapas: antes e depois do processo formativo.

De modo geral, no que se refere aos conhecimentos manifestados pelas professoras na gestão de tarefas matemáticas, os dados empíricos apresentados, possibilitaram constatar que as professoras ao gestionarem as tarefas matemáticas na sala de aula apresentam dificuldades nos conhecimentos didático-matemáticos. Foi possível perceber que mesmo com a devida formação acadêmica para atuar com a matemática dos Anos Iniciais, as professoras 


\section{A GESTÃo DO PLANEJAMENTO DE TAREFAS MATEMÁTICAS POR PROFESSORAS DOS ANOS INICIAIS}

apresentaram uma idoneidade epistêmico - cognitiva em grau de médio a baixo, revelando fragilidades no domínio desses elementos que estão diretamente relacionados ao domínio de conteúdos. As dificuldades ficaram evidentes nos discursos das professoras nas entrevistas e nos encontros de formação ao tratarmos sobre conteúdos matemáticos, no trato com a matemática institucionalizada e com a resolução dos conflitos cognitivos e epistêmicos dos alunos que surgiram nas aulas executadas. Visualizamos, por exemplo, na fala de uma das professoras quando foi questionada se sentia alguma dificuldade ao planejar as tarefas matemáticas:

Professora Flor: "Tem conteúdo que sinto dificuldades, pois não domino muito [...] Tenho dificuldade tanto com relação ao domínio do conteúdo, como também como passar esse conteúdo". [Depoimento recolhido por meio da entrevista antes do processo formativo]

Essas constatações corroboram as preocupações de Nacarato et al (2011), dentre outros pesquisadores, com relação ao domínio de conhecimentos do professor que ensina Matemática nos anos iniciais do Ensino Fundamental. Os autores afirmam que existe uma falta de domínio de conhecimento do conteúdo a ser ensinado, por parte dos professores, e que "é impossível ensinar aquilo sobre o que não se tem um domínio conceitual” (NACARATO et al, 2011, p. $35)$.

No que se refere à gestão do planejamento, os dados da nossa pesquisa indicam que as professoras, embora reconheçam a importância do planejamento o processo de ensino e aprendizagem, demonstram dificuldades ao planejarem devido à falta de domínio de conhecimentos didático - matemáticos, e, por conseguinte, durante o planejamento estudam pouco ou não estudam, e normalmente refutam os conteúdos que tem dificuldades, em vez de estudá-los para trabalhar com os alunos. Em depoimento colhido, por meio da entrevista, antes do processo formativo a professora Flor afirmou: "Quando eu consigo dominar o conteúdo, eu trabalho, se não, não trabalho". Além disso, ao planejarem, as professoras atribuem um peso maior às experiências de trabalho com o conteúdo do que ao currículo propriamente dito, demonstrando uma falta de articulação com a faceta ecológica do conhecimento didático matemático. Premissa que é ratificada nos discursos das professoras quando foram questionadas se consideraram os documentos curriculares oficiais (BNCC, Proposta Curricular) para planejarem a sequência matemática solicitada. 


\section{A GESTÃO DO PLANEJAMENTO DE TAREFAS MATEMÁTICAS POR PROFESSORAS DOS ANOS INICIAIS}

Professora Flor: Eu dei uma olhadinha no plano de curso, mas nos outros, não. [...] isso aí mesmo de considerar os documentos curriculares seria muito importante, mas vou ser sincera com vocês, nem sempre a hora que vou planejar eu olho, a gente peca nisso aí né?

Professora Carla: Eu também dei uma olhadinha no plano de Curso, mas lembrei também de alguns enfoques dados pela Coordenadora ano passado e uma apostilhinha que ela deu, mas, considerei mais a base que já tenho em dar este conteúdo. [Depoimentos recolhidos no $2^{\circ}$. Encontro formativo]

No contexto de dificuldades pontuadas, ficou evidente a necessidade de as professoras incorporarem em seu fazer pedagógico diário a prática de estudos e reflexões profissionais fazendo desta prática, parte integrante do processo de planejamento e de ensino.

Sobre a escolha das tarefas, normalmente as professoras se prendem ao livro didático ou recorrem à internet.

No que concerne à idoneidade didática nas duas sequências de tarefas planejadas pelas professoras sobre o conteúdo medidas de comprimento, os resultados são expressos no quadro a seguir:

Quadro 1: Análise das idoneidades didáticas nas sequências de tarefas planejadas

\begin{tabular}{|c|c|c|}
\hline Idoneidade didática & Indicadores empíricos & Grau de adequação \\
\hline Epistêmica & $\begin{array}{l}\checkmark \text { Contempla conceitos (comprimentos variados) e } \\
\text { linguagem clara; (Seq. 2); } \\
\checkmark \text { Oferece pouco desafio, pouco estímulo à argumentação, } \\
\text { às justificativas das ideias matemáticas e à autonomia do } \\
\text { aluno. }\end{array}$ & $\begin{array}{l}\text { Grau } \\
\text { Médio - Baixo }\end{array}$ \\
\hline Cognitiva & $\begin{array}{l}\checkmark \text { Não contempla a zona de desenvolvimento proximal e as } \\
\text { diferenças individuais dos alunos; } \\
\checkmark \quad \text { Considera os conhecimentos prévios dos alunos. }\end{array}$ & $\begin{array}{l}\text { Grau } \\
\text { Médio- - Baixo }\end{array}$ \\
\hline Interacional & $\begin{array}{l}\checkmark \text { Não prevê oportunidades para incentivo à comunicação, } \\
\text { ao diálogo aluno - aluno, privilegiando o diálogo professor } \\
- \text { aluno; } \\
\checkmark \text { Apresentam linguagem clara e compreensível aos } \\
\text { alunos. }\end{array}$ & Grau Médio \\
\hline Mediacional & $\begin{array}{l}\checkmark \text { Limitada descrição de instrumentos manipulativos de } \\
\text { medida de comprimentos (Seq. 1); } \\
\checkmark \text { Recursos e materiais escolhidos, adequados e } \\
\text { condizentes com o desenvolvimento das tarefas (Seq. 2); } \\
\checkmark \text { Não prevê tempo e/ou tempo mal distribuído entre as } \\
\text { tarefas. }\end{array}$ & $\begin{array}{c}\text { Grau } \\
\text { Médio - Baixo }\end{array}$ \\
\hline
\end{tabular}




\begin{tabular}{|l|l|l|}
\hline Emocional & $\begin{array}{l}\checkmark \text { Conteúdos distantes das potencialidades dos alunos } \\
\text { desmotiva a sua solução. }\end{array}$ & Grau Médio \\
\hline Ecológica & $\begin{array}{l}\checkmark \text { Cumprimento parcial do currículo; } \\
\checkmark \text { Não contempla a interação do conteúdo com outras } \\
\text { áreas do conhecimento. }\end{array}$ & Grau Médio \\
\hline
\end{tabular}

Fonte: Dados da pesquisa, 2018.

\section{Legenda:}

Idoneidade alta: o descritor foi todo contemplado no planejamento da sequência de tarefas;

Idoneidade média: o descritor foi razoavelmente contemplado no planejamento da sequência de tarefas;

Idoneidade baixa: o descritor não foi contemplado no planejamento da sequência de tarefas.

Desse modo, no que se refere à idoneidade didática manifestada pelas professoras no processo de planejamento, antes do processo formativo, de modo geral, avaliamos em grau moderadamente médio as idoneidades interacional, emocional e mediacional. E as lacunas apresentadas nas idoneidades epistêmica, cognitiva e ecológica, nos permitiram avaliá-las em grau médio - baixo. São aspectos que consideramos limitadores à gestão do planejamento de tarefas pelas professoras.

Após o processo formativo, com o replanejamento da sequência de tarefas, apresentouse alguns avanços no processo de gestão do planejamento, sobretudo, no que tange aos critérios de idoneidade didática. As modificações feitas passaram a contemplar elementos da idoneidade interacional, elevando-a para o grau moderadamente alto; da idoneidade ecológica, elevando esta para o grau moderadamente alto e as idoneidades epistêmica e cognitiva, elevando-as assim, para o grau médio.

Assim, concluímos que a prática de estudos, o domínio do conhecimento e o grau de idoneidade didática, manifestados pelo professor estão estreitamente relacionados. Contexto que corrobora ao que afirma, Serrazina $(1999$, p. 140) “[...] há uma relação muito estreita entre o conhecimento do professor e o seu ensino, e que este afeta o que ele faz na sala de aula e o que os alunos aprendem”. Portanto, quanto mais o professor estuda, mais ele se apropria do conhecimento e maior será o grau da Idoneidade Didática presente na gestão do planejamento das tarefas. 


\section{A GESTÃo DO PLANEJAMENTO DE TAREFAS MATEMÁTICAS POR PROFESSORAS DOS ANOS INICIAIS}

\section{Considerações Finais}

Analisar a gestão de tarefas matemáticas, possibilitou assumir que, em qualquer que seja o contexto, a gestão de tarefas requer planejamento, implementação e avaliação didaticamente idôneos, com destaque para o planejamento das tarefas, pois este constitui um processo de extrema relevância para o sucesso da qualidade da condução do ensino desenvolvida pelo professor em sala de aula e, por conseguinte, o sucesso do aluno na aprendizagem dos conteúdos.

Os elementos apresentados nos resultados da nossa pesquisa nos permitem ainda, fazer uma reflexão em torno das formações continuadas promovidas pelas Secretarias de Educação. Por mais que têm sido oferecidas essas formações, no que tange às suas concepções e propósitos, elas precisam ser repensadas, pois, as fragilidades de domínio do conteúdo matemático, apresentadas pelos sujeitos da nossa pesquisa, trazem um indicativo de que embora sejam professoras experientes, com formação inicial adequada, com participações constantes em ações de formação, ainda existe uma lacuna a ser preenchida na formação dessas professoras.

Ademais, do ponto de vista da metodologia adotada na investigação - A Pesquisa Ação Estratégica-consideramos que esta atingiu o seu propósito, pois ao menos na realidade investigada, ela cumpre a sua função de proporcionar melhorias efetivas na prática das professoras, através do conhecimento produzido. Nesse sentido, o movimento de pesquisa ação foi imprescindível ao processo de reflexão crítica, a partir da qual as professoras participantes passaram a se perceberem não apenas como participantes de uma pesquisa, mas como protagonistas da ação de uma formação continuada e, corresponsáveis pelo desenvolvimento e pela produção desta investigação. Nesse caso, a pesquisa cumpriu o seu papel investigativo e também formativo.

\section{REFERÊNCIAS}

BRASIL. Ministério da Educação. Base Nacional Comum Curricular. 2017. Disponível em: <http://basenacionalcomum.mec.gov.br/wp-content/uploads/2018/02/bncc-20dez-site.pdf >. Acesso em: 23 de julho de 2018.

Ministério da Educação. Instituto Nacional de Pesquisas Educacionais Anísio Teixeira. Resultados do Censo Escolar de 2015. Brasília. Disponível em: 〈http//www.inep.gov.br〉. Acesso em: 17 setembro de 2018. 


\section{A GESTÃo do PLANEJAMENTO DE TAREFAS MATEMÁTICAS POR}

BREDA, Adriana; FONT, Vicenç, LIMA, Valderez Maria do Rosário. A noção de idoneidade didática e seu uso na formação de professores de matemática. JIEEM - Jornal Internacional de Estudos em Educação Matemática, n. 8 (2). p. 1-41, 2015.

CHIAVENATO, Idalberto. Introdução à teoria geral da administração. 7.ed. rev. e atual. Rio de Janeiro: Elsevier, 2003.

CURY, Carlos Roberto Jamil. A gestão democrática na escola e o direito à educação. Revista Brasileira de Apolítica e Administração da Educação (RBPAE). V. 23, n.3, set. /dez. 2007. p. 483-496. Porto Alegre: ANPAE, 2007.

DIAS, Emerson de Paulo. Conceitos de gestão e administração: uma revisão crítica. Revista Eletrônica de Administração-Facef, v.01, ed. 01, julho/dezembro 2002.

FIORENTINI, Dario; LORENZATO, Sergio. Investigação em educação matemática: percursos teóricos e metodológicos. 3. Ed. Ver. Campinas, SP: Autores Associados, 2012.

GAUTHIER, Clermont [et al.]. Trad. Francisco Pereira. Por uma teoria da pedagogia: pesquisas sobre o saber docente (Coleção Fronteiras da educação). 3 ed. Ijuí: Ed. Unijuí, 2013. 480p.

GODINO, Juan. Un enfoque ontológico y semiótico de la cognición matemática. Recherches en Didactique des Mathématiques, Vol. 22, nº 2.3, pp.237-284, 2002.

Categorias de análisis de los conocimientos del profesor de Matemáticas. UNION, Revista Iberoamericana de Educación Matemática, n.20, p.13-31, 2009.

Indicadores de la idoneidad didáctica de procesos de enseñanza y aprendizaje de las matemáticas. XIII Conferência Interamericana de Educação Matemática (CIAEM-IACME), Recife (Brasil), 2011.

GODINO, J D., BATANERO, C., FONT, V; GIACOMONE, B. (2016). Articulando conocimientos y competencias del profesor de matemáticas: el modelo CCDM. En C. Fernández, J. L. González, F. J. Ruiz, T. Fernández y A. Berciano (Eds.), Investigación en Educación Matemática XX (pp. 288-297). Málaga: SEIEM.

GUSMÃO, Tânia Cristina Rocha Silva (2016). Desenho de tarefas para o desenvolvimento da cognição e metacognição matemática. In: NEVES, Anderson Souza ... (org.) ... [et al.] Ensino e Didática das Ciências (Coleção Ensino, filosofia e história das ciências). Salvador: EDUFBA, 2016, p. 183-193.

LUCK, Heloísa. Dimensões da Gestão Escolar e suas Competências. Curitiba: Positivo, 2009.

NACARATO, Adair Mendes; MENGALI, Brenda Leme da Silva; PASSOS, Carmén Lúcia Brangaglion (Coord.). A matemática nos anos iniciais do ensino fundamental: Tecendo fios do ensinar e do aprender. Belo Horizonte: Autêntica, 2011. (Coleção Tendências em Educação Matemática).

POCHULU, Marcel; FONT, Vicenç. e RODRIGUEZ Mabel. Criterios de diseño de tareas para favorecer el análisis didáctico en la formación de profesores. Actas del VII CIBEM. Montevideo: Uruguai. 2013.

PONTE, João Pedro da. Gestão curricular em Matemática. Em: GTI (Ed.), O professor e o desenvolvimento curricular. Lisboa: APM, p. 11-34, 2005. 


\section{A GESTÃo do PLANEJAMENTO DE TAREFAS MATEMÁTICAS POR}

ROLDÃO, Maria do Céu. Gestão Curricular: Fundamentos e Práticas. Lisboa: Ministério da Educação (ME). Departamento da Educação Básica (DEB), 1999 (Coleção Reflexão Participada; 6)

ROLDÃO, Maria do Céu; Almeida, Sílvia de. Gestão Curricular para a autonomia das Escolas e professores. Lisboa: Ministério da Educação (ME). Direção-Geral da Educação (DGE), 2018 (Autonomia e Flexibilidade CURRICULAR).

SERRAZINA, Maria de Lurdes. Planificação do ensino e aprendizagem da matemática. In: INVESTIGAÇÃO, G. G. D. T. D. (Ed.). A prática dos professores: Planificação e discussão coletiva na sala de aula. Lisboa: Associação de Professores e Matemática, 2017.

SERRAZINA, Maria de Lurdes. Reflexão, conhecimento e práticas lectivas em Matemática num contexto de reforma curricular no $1^{\circ}$ ciclo. Quadrante, 9, 139-167, dez.1999.

SOUSA, Jorge Ramos de. [et al.]. Contribuições do (re) desenho de tarefas para aproximação da matemática com o entorno social da escola. Revista Práxis Educacional, v. 15, n. 33, p. 444-471, jul./set. 2019, ISSN: 21782679

SOUSA, Jorge Ramos de. (Re) desenho de tarefas para articular os conhecimentos intra e extramatemáticos do professor. Dissertação (Mestrado em Educação Científica e Formação de Professores). Universidade Estadual do Sudoeste da Bahia - Campus Universitário de Jequié, Jequié, Bahia, 2018.

STEELE, Diana. F. Vozes entusiastas de jovens matemáticos. Educação e Matemática, n. 62, p. 39-42, mar. /abr., 2001.

STEIN, Mary Kay. [et al.]. Implementing standards-based mathematics instruction: a casebook for professional development. New York: Teachers College Press, 2009.

TRIPP, David. Pesquisa-ação: uma introdução metodológica. Educação e pesquisa, v. 31, n. 3, p. 443-466, 2005. https://doi. org/10.1590/S1517-97022005000300009.

VASCONCELOS, Celso dos Santos. Planejamento: Projeto de Ensino e aprendizagem e Projeto Político Pedagógico. (Org.). Campinas/SP: Papirus. 2012.

WADSWORTH, Barry J. Inteligência e Afetividade da Criança da Teoria de Piaget. 3 ed. São Paulo, 1994.

WEINSTEIN, Carol Simon; NOVODVORSKY, Ingrid. Gestão da sala de aula: lições da pesquisa e da prática para trabalhar com adolescentes. Porto Alegre: AMGH, 2015. 


\section{A GESTÃO DO PLANEJAMENTO DE TAREFAS MATEMÁTICAS POR PROFESSORAS DOS ANOS INICIAIS}

\section{SOBRE AS AUTORAS}

Tânia Cristina Rocha Silva Gusmão é Doutora em Didática da Matemática pela Universidade de Santiago de Compostela (USC). Professora na Universidade Estadual do Sudoeste da Bahia (UESB), no Programa de PósGraduação em Educação Científica e Formação de Professores e no Programa de Pós-Graduação em Ensino, ambos na UESB. Coordenadora do Grupo de Estudos e Pesquisas Museu Pedagógico: Didática das Ciências Experimentais e da Matemática (GDICEM/UESB).

Endereço eletrônico: professorataniagusmao@gmail.com

ORCID 0000-0001-6253-0435

Lindomar Santana Aranha Pereira é Mestre em Ensino pela Universidade Estadual do Sudoeste da Bahia (UESB). Técnica em Assuntos Educacionais no Instituto Federal de Educação, Ciência e Tecnologia Baiano (IF Baiano) Campus Guanambi. Professora do Ensino Fundamental na Rede Municipal de Ensino de Guanambi - Bahia. Integrante do Grupo de Estudos e Pesquisas Museu Pedagógico: Didática das Ciências Experimentais e da Matemática (GDICEM/UESB).

Endereço eletrônico: linda.santana@ifbaiano.edu.br ORCID: https://orcid.org/0000-0002-1067-336X

Recebido em: 25/04/2020

Aprovado em: 20/05/2020

Publicado em: 01/07/2020

\section{Notas}

\footnotetext{
${ }^{i}$ Para Gusmão (2016), desenho de tarefas é o "processo de elaboração, criação e preparação de situações matemáticas a serem aplicadas em sala de aula".

ii A metacognição pode ser entendida como o conhecimento que uma pessoa tem acerca de seus próprios processos e produtos cognitivos. Tanto a cognição como a metacognição emergem das experiências que uma pessoa vai adquirindo em vários contextos como, por exemplo, com as tarefas matemáticas que realiza em sala de aula (GUSMÃO; CAJARAVILLE; FONT; GODINO, 2014).

iii Índice de Desenvolvimento da Educação Básica, criado em 2007, pelo Instituto Nacional de Estudos e Pesquisas Educacionais Anísio Teixeira (Inep), formulado para medir a qualidade do aprendizado nacional e estabelecer metas para a melhoria do ensino.
} 